\title{
Social Media Research Analysis of China Based on Informetrics*
}

\author{
Xiaobo Tang, Hua Hu \\ School of Information Management, Wuhan University, Wuhan, China \\ henryhu@whu.edu.cn
}

\begin{abstract}
In recent years, the emergence of social media had a profound impact to the informatics, especially information technology and information management. This paper summarized the background of social media and related concepts. Then the paper analyse the domestic literature of social media by bibliometric. Last, the paper using social network analysis to analyze social media research projects. This paper wanted to find the basic research theory, research perspectives and research topics of social media..

Index Terms - Social Media, Social Network, literature analysis, project analysis
\end{abstract}

\section{Introduction}

With the rapid development of web2.0 technology and network technology, the popularity and prevalence of Social Media has become a global information dissemination which is sharing of vital resources and become an indispensable part of life. Social media has changed the way of the life and communication which people used to by a "visible" speed. Especially in recent years, various forms of social media present as a convergence trend which means all the social media integrated into the network application [1]. From the Middle East Revolution to Obama's re-election [2], Social media demonstrate its strong strength and unparalleled charm in all over the world. And it is also popular in the current microblog anti-corruption storm in China. It is changing our world based on a variety of characteristics which social media brings from the emerging technologies. The social media research and using is deepen and promoted by the area of business, academia, politicians to make a better service of humanity.

Social media research has penetrated into everywhere of our life. And it not only brought rare opportunities for enterprise development and social progress, but also accompanied with greater challenges and problems. This paper intends to study the drivers of social media, the concept of social media and the domestic research of social media to make a comprehensive study of social media, in order to promote the research and application of social media for future.

\section{What is Social Media?}

Although social media's history is more than 30 years, but its concept has not yet been a uniform definition. The scholars from different areas have defined social media from different angles.
Jan H. Kietzmann make a definition of social media such as mobile technology for the application or browser-based technologies which is in order to create, discuss and revise UGC and created by the high share of the platform [3].Andreas M. Kaplan thinks that social media is a set of ideas and technology-based applications building on Web2.0 which purpose is to create and share UGC [4]. These scholars defined social media as a tool for sharing information.

Other scholars such as Antony Mayfield make a definition of social media by distinguishing the social media and the traditional media. He indicate that social media is a new online media which give users a great space and emphasizes that user participation is the core of social media [5]. This definition from the attribute of media has also been recognized by many scholars, such as Zheng Xiang [6], Ren Mengshan, etc. [7].

A large part of scholars agree the definition of social media from the destination, such as Erik Qualman the author of "social media change the world", his think that social media is some technologies and platforms what to help people easily keep in touch with friends [8]. The social media is defined as a set of online collection tools which is designed for the conduct of social communication by Hansen Shneiderman, etc [9].

While domestic and foreign scholars define social media from a variety of angles with different interpretations. Their definition does not conflict, but complement each others. They only focus from different areas. This paper concludes the current definition of social media. Then there are three elements of social media has been found. First social media is a broad participation of a new type of media. Second it is aimed at strengthening the UGC sharing and interpersonal communication. Thirdly, it is the application based on Web2.0 and mobile technology or tools.

In practice, there are various types of social media such as blog, microblog, social sharing services s, text messaging, discussion forums, collaborative editing tool, virtual worlds such, social networking services etc. [4].

\section{Social Media Research Literature Analysis}

In this paper, the article from China Journal Net (CNKI) was used as the source. Then the time, research subject and related academic field of the published literature has been analyzed. We select "social media", "social media," "social media" as the theme, then use "SU = 'social media' OR SU =

\footnotetext{
* This work is partially supported by NSFC Grant \#71273194 to Xiaobo Tang.
} 
'social media' OR SU = 'social media' OR SU = 'social media'" as the retrieval language. A total of 2132 results has been received. After filter out irrelevant documents and themes, such as "building a harmonious society: The media should do what self-adjustment " etc. We eventually get 1318 search results which shown in Table I.

TABLE I Social media's distribution of literature of published articles

\begin{tabular}{|c|c|c|c|}
\hline Years & Articles & Key Word & Percentage \\
\hline 2007 & 2 & Social Media, Web2.0 & $0 \%$ \\
\hline 2008 & 11 & Social Media, Propagate, Blog, SNS & $1 \%$ \\
\hline 2009 & 69 & $\begin{array}{l}\text { Social Media, Government, Blog, } \\
\text { Marketing }\end{array}$ & $6 \%$ \\
\hline 2010 & 132 & Social Media, Blog, Marketing & $9 \%$ \\
\hline 2011 & 456 & $\begin{array}{l}\text { Social Media, Blog, Social Media } \\
\text { Marketing }\end{array}$ & $34 \%$ \\
\hline 2012 & 647 & $\begin{array}{l}\text { Social Media, Micro-blog, Micro-blog } \\
\text { Marketing, Government Micro-blog }\end{array}$ & $50 \%$ \\
\hline Totel & 1317 & & $100 \%$ \\
\hline
\end{tabular}

We can directly find out the amount of social media in 2007-2008 growth slow, and rapid in 2009. That means in the year 2007, there are no studies on social media, the similar research were around the topic of Web2.0, UGC and blog, etc. 2007, the researchers gradually from Web2 .0 shift to social media. Social media applies in various fields to discuss. The emergence of micro-blog caused academic pursuit after 2008 which is also brings boom of social media research. The research topic gradually changes from concept introduction and simple application to the application in business and social areas.

We rank the keyword of social media article shows in Table II, and find that social media research currently selected object is the main micro-blog from the theory of communication. The research mainly focused on the areas of business and society.

TABLE II Keyword Ranking

\begin{tabular}{|l|l|l|}
\hline Rank & Keyword & Number \\
\hline 1 & Social Media & 125 \\
\hline 2 & Social Network & 53 \\
\hline 3 & Micro-blog & 50 \\
\hline 4 & Micro-blog Marketing & 19 \\
\hline 5 & Social Media Marketing & 12 \\
\hline 6 & New Media & 10 \\
\hline 7 & Transmission & 9 \\
\hline 8 & Internet Public Opinion & 8 \\
\hline 9 & Internet Marketing & 8 \\
\hline 10 & Government Micro-blog & 7 \\
\hline
\end{tabular}

In this paper, we choose 423 literatures which has been cited more than one times from the 2132 results that we retrieved. Then we make an analysis of citation and crosscitation of chosen literature and the literature the cited. Finally, we use cluster analysis to study the important research areas and the basic theory of social media. The visualization result as shown in Figure 1.

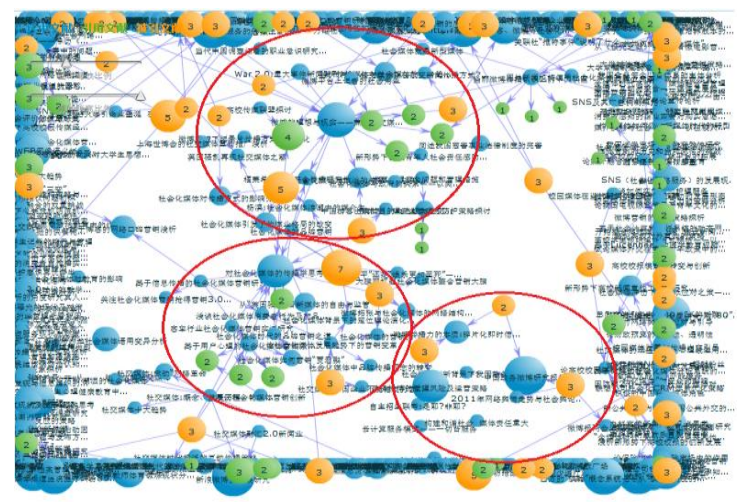

Fig. 1 The visualization of citation and cross-citation

From Figure 2, we can easily find out that there are three main categories of the research of social media in China .The first category is to study social media from a point of view of sociological which is trying to build social media with people, society, government relations.The important article in this category is "The ideal and the reality of social media- On social media construction of public space three disturbing factors" [10].The second category is the spread of science and economics from the perspective of social media propagation characteristics and commercial applications, including commercial applications mainly in social media marketing The important articles in this category are "For social Media Communication Science" [2] and "Based on the user's social psychology media marketing impact assessment "[11]. The third category discussed from multiple perspectives of social media on government and countermeasures, especially the government how to deal with unexpected events network public opinion information disclosure issues.The most important articles in this category are "Chinese government micro-blog research report" [12] and "On the Iranian" Twitter revolution "in social media political communication function" [7] . In addition to the three major categories of more focused studies, there are on the developments and trends in social media research, as well as social media in education, health care, real estate and other two areas of research and so on.

The literature cited at the center of important documents, including the book "Communication Course" [13], the book "Fear of freedom"[14], and the book "Structural transformation in the public domain"[15]. From three important documents cited social media can be obtained based on the current study's principal theoretical basis from the media, psychology and sociology.

From the results, there are merely research articles of social media from a technical perspective and in the comprehensive study of social media applications. But we can find the social media application technology research has 
become important direction of social media research from result of the trend of referenced literature.

\section{Analysis of social media research project}

In this paper, the research project data is from the website of the National Natural Science Fund Committee and the National Planning Office of Philosophy and Social Sciences. We collected the data by searching the topic or title which contains "social media", then found a total of 82 items including 10 Social Science Fund Project and 72 Natural Science Fund Project.

There are two class projects in Natural Science Foundation Faculty, 47 projects in Information Science Department and 25 projects in Department of Management Sciences. Philosophy and Social Science Fund project for a major class of disciplines, including Journalism and Communication Studies, Library, Information and Documentation Science. In this paper, the statistical analysis of each project keywords can be a good response to the current domestic research projects focus areas and future development trend.

Through the statistics of the 82 project information, the paper gathered 272 keywords which total appears 337 times. There are 4.6 keywords per project. Keywords are from 3 to 5 and five keywords article are the largest, accounting for $65 \%$ of total. In order to accurately analyze research themes, the paper carried the extracted keyword synonyms, upper and lower word processing, merge, received a total of 199 words.

Then we selecting the keywords which occur more than two times to construct a $33 * 33$ co-word matrix shown as in TableIII by using the bibliometric tool bibexcel [16].

TABLE III High-frequency words of the word matrix (Partial)

\begin{tabular}{|l|c|c|c|c|c|}
\hline & $\begin{array}{c}\text { Social } \\
\text { Media }\end{array}$ & $\begin{array}{c}\text { Social } \\
\text { Network }\end{array}$ & $\begin{array}{c}\text { Micro } \\
\text {-blog }\end{array}$ & $\begin{array}{c}\text { User } \\
\text { Behavior }\end{array}$ & $\begin{array}{c}\text { Information } \\
\text { Transformation }\end{array}$ \\
\hline Social Media & 0 & 5 & 0 & 3 & 2 \\
\hline Social Network & 5 & 0 & 0 & 2 & 1 \\
\hline Micro-blog & 0 & 0 & 0 & 1 & 0 \\
\hline User Behavior & 3 & 2 & 1 & 0 & 1 \\
\hline $\begin{array}{l}\text { Information } \\
\text { Transformation }\end{array}$ & 2 & 1 & 0 & 1 & 0 \\
\hline $\begin{array}{l}\text { Information } \\
\text { Mining }\end{array}$ & 1 & 0 & 4 & 0 & 0 \\
\hline
\end{tabular}

After importing co-word matrix into the analysis software ucinet, we can get the generation of the present graphical visualization keyword, as shown in Figure 3. Seen from Figure 3 , the centrally located semantics, microblogging, social networking, information dissemination, user behavior, user interest, information retrieval, information recommendation, knowledge discovery, theme detection, network public opinion, information retrieval and other keywords. These are the hot topic which the current domestic research projects has focused on.

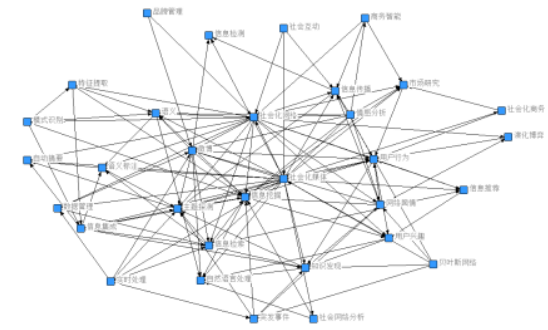

Fig. 3 The co-occurrence graph of high-frequency keywords

Using N-Cliques factions analysis to study the Co-word matrix of high-frequency keywords, setting $\mathrm{N}=1$, the minimum data set as 5 , then we get 21 small groups as the clustering results shown in Figure 4. It can be seen that domestic social media research direction of the project factions more concentrate and each has its own links. It can be speculated that the current domestic social media research encountered a technical bottleneck, has not yet achieved breakthrough results. By analyzing the judge exclude duplicates, we found that social media research can be divided into two schools: Technical School and behavioral school. Technical school focuses on technology to achieve through better use of social media and behavioral school will focus on how to make better use of social media to create value.

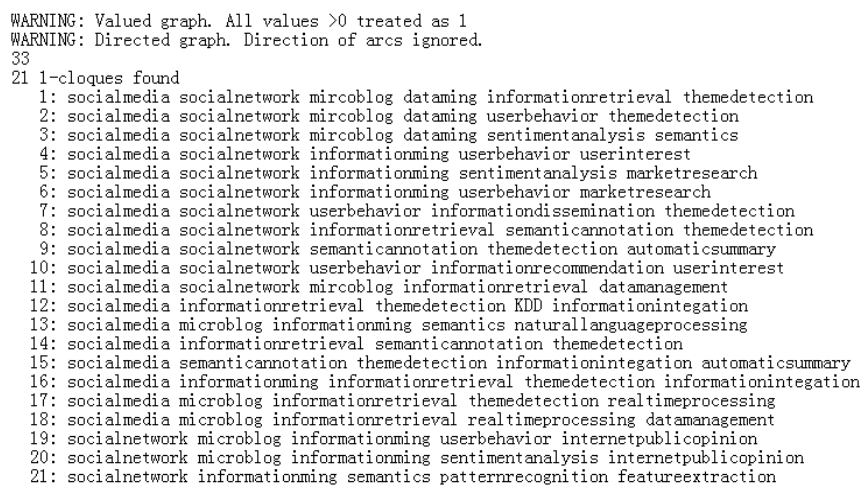

Fig. 4 Social media project keywords factions analysis chart

Using cluster analysis, factional analysis and subgroup analysis on the keywords, we find six subgroups of social media research shown in Figure 5.

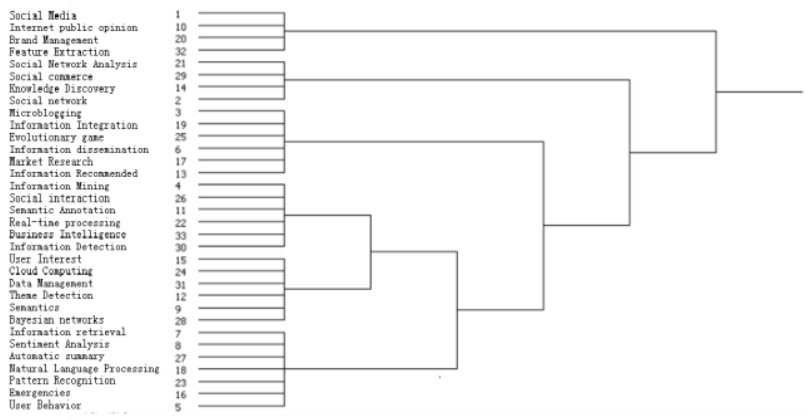

Fig. 5 Social media research projects words cluster analysis diagram 
From the result, we can find that although the domestic research factions are not much, but at the same faction research emphases also vary. The main research topics behavioral school group there are three, the first is around social media and user interest with the corresponding push, including: social networking, user behavior, user interest, information, recommendations, evolutionary game, and the second is built around the use of social media to carry out market research, including business intelligence, market research, social commerce, sentiment analysis, and the third is focused on the study of propagation effects of social media and brand, the relationship between propaganda, such as social interaction, information dissemination, brand management.

Technical school in the study of social media has on three thematic clusters, the first is around social media automatically collect information technology research, including natural language processing, semantic, feature extraction, pattern recognition, information mining, social networks analysis; the second is to focus on social media information for automatic processing and organizations, including information retrieval, semantic annotation, automatic summarization, information integration, data management, topic detection, real-time processing; third is for social media information automatic use, including network public opinion, knowledge discovery.

The above analysis results can infer that in the current domestic social media research project also focused social media how to effectively collect the information and how to conduct a preliminary social media business use two aspects, and therefore did not an effective technical means or mature business model to effectively against the value of social media in the excavation and utilization. Meanwhile, research is also focused on the perspective of information science and management science perspective focuses on these two social media contact their research perspective, the lack of crosscutting from an interdisciplinary perspective on social media research. It can be concluded, the current domestic social media systematic study also focused on the initial stage, all aspects are still immature, there is a large research space and research value waiting for us to explore.

\section{Conclusion}

We review the basic concepts of social media induce the three basic elements of social media.The the paper apply bibliometric analysis to social media literature, we found that social media research focuses on two aspects--business and society.Then the paper found that the communication theory, psychology theory and the sociology theory are the three basis theoretical categories for research.

The research divided the social media researcher into two schools by informetrics analysis, the one is technical school and the other is behaviour school.After that we find out the research topics of the two school.

Finally, the paper make the summary of the results of econometric analysis, we can see that domestic research literature although many and wider coverage, but did not form an important research and systems. The domestic projects related studies more in-depth, but did not form directly into a social and commercial applications system. By support of Natural Science Foundation of China, we will make a further study of social media in technology and make a better use of the social media in future.

\section{Acknowledgment}

This work was supported by Natural Science Foundation of China," Social Media Integration retrieval and semantic analysis method", grant number 71273194.

\section{References}

[1] Peng Lan, "Social,media and the dual challenges of media convergence," Press Circles, vol.01.pp.2-5,Jan 2012

[2] Sun Nannan, "Communication Science of Social Media,"News lovers, vol.17, pp.16-17, May 2009.

[3] Kietzmann, Jan H., et al, "Social media? Get serious! Understanding the functional building blocks of social media," Business Horizons, vol. 54, no. 3, pp.241-251,Jan 2011

[4] Kaplan, Andreas M., Michael Haenlein, "Users of the world, unite! The challenges and opportunities of Social Media." Business horizons, vol. 53, no. 1.pp. 59-68, Sep 2009.

[5] Antony Mayfield, What is Social Media, Icrossing ebook Publish Spannerworks, 2008, pp.3-5.

[6] Xiang, Zheng and Ulrike Gretzel, "Role of social media in online travel information search,” Tourism management, vol. 31, no. 2, pp.179-188, April 2010

[7] Ren Mengshan and Zhu Zhenming, "The political communication function of Iran 'Twitter revolution' in social media," The international press, vol.09, pp. 26-30, Sep 2009

[8] Qualman, Erik, Socialnomics: How social media transforms the way we live and do business, 1st ed., Wiley, 2012, pp.31-39.

[9] Hansen, Derek, Ben Shneiderman, and Marc A. Smith, Analyzing social media networks with NodeXL: Insights from a connected world, 2nd ed., Morgan Kaufmann, 2010, pp.66-69

[10] Yuan Jinghua, "The ideal and the reality of micro-blog -- social media to construct public space of the three variables," Journal of Zhejiang Normal University (SOCIAL SCIENCE EDITION),vol. 6, pp.20-25, Jun 2010

[11] Li Zhen,"Evaluation on social media marketing effect the user psychology, "Jiangsu business based on the theory, vol.7, pp.110-112, July 2010.

[12] Zhang Zhian, Jia Jia, "Chinese government micro-blog Research Report “, Modern Communication, vol.3, pp.58-58, March 2011.

[13] Guo Qingguang, Communication Tutorial, 3rd ed.,Beijing: Renmin University of China Press, 1999.

[14] Erich Fromm, The Fear of Freedom, Routledge Press,2001.

[15] Cox, Helmut. Strukturwandel der öffentlichen Wirtschaft unter dem Einfluss von Marktintegration und europäischer Wettbewerbsordnung, BWV. Berliner Wiss.-Verlag, 2005.

[16] Jiang Chunlin, Chen Yuguang, "Transfor m CSSCI Data to Bibexcel Data to Actualize Co-occurrence Matrix and A Case Study," Library Journal, vol.29, no.4, pp.58-63, April 2010. 